\title{
EL PERSONAJE DE LA DUQUESA EN EL TEATRO FRANCÉS CONTEMPORÁNEO
}

Las numerosas transposiciones teatrales de El ingenioso hidalgo don Quijote de la Mancha que han salido a luz en Francia en los años 90 son la prueba de la presencia del personaje inmortalizado por Cervantes y de la fascinación que sigue ejerciendo en nuestro país. El paso del libro al tablado necesita importantes elipsis y muchos protagonistas de la novela cuya influencia no es imprescindible para la progresión dramática han desaparecido en las obras dramáticas modernas. Sin embargo, la duquesa y su esposo figuran ad nominem o a través de papeles condensados en la mayoría de las adaptaciones.

Voy a evocar solamente tres piezas: sus autores - Georges Berdot, Nele Paxinou y Maryse Lefebvre- no tienen la envergadura de los grandes maestros, pero la calidad de su trabajo y la diversidad de sus respectivas maneras de enfocar ofrecen un excelente soporte para el descubrimiento de las técnicas que gobiernan el proceso de transposición y para el análisis del papel particular asignado a la pareja ducal tanto por el novelista como por los dramaturgos ${ }^{1}$.

Desde la publicación de las primeras aventuras del caballero de la Triste Figura, autores tan famosos como Shakespeare (1613) y Guillén de Castro (1618) se adueñaron de la obra mayor de Cervantes para transponerla al tablado. Este proceso, ininterrumpido hasta hoy, subraya la profunda teatralidad de la novela y

1 El texto integral de estas piezas, inédito todavía en Francia, figura en los anejos de mi tesis: Don Quichotte théâtralisé au XX⿳亠丷冖 siècle. Université de Toulouse II, 1998. 
confirma el juicio que Azorín expresaba sobre el manco de Lepanto $^{2}$ :

"Te has ufanado siempre de ser hombre de teatro. Tenías mucha razón. El Quijote es la novela de un hombre de teatro.»

En efecto, si el teatro se muestra sin ambages en el «Retablo de Maese Pedro» o en las "Cortes de la Muerte», tambien se incorpora en la propia diégesis y muchos personajes se comportan como auténticos escenógrafos en un género donde predominan las comedias de diversión.

En esta sección, un lugar privilegiado está reservado al duque y a la duquesa. Estos directores excelentes disponen además de señalados actores improvisados cuyo talento hace maravillas y entre los cuales se destacan Altisidora y la dueña Dolorida. El ingenioso hidalgo por fin puede creerse verdadero caballero y verse tratado como tal. El montaje de la gigantesca burla ducal confiere a don Quijote un nuevo estatuto: si antes desformaba el mundo sensible a través de sus propios fantasmas, ahora percibe una realidad manipulada y alterada por la acción de terceras personas conscientes. Las cosas no son las que parecen ni los individuos lo que «pretenden».

La duquesa y su esposo se libran pues de la elipsis que afecta, en el marco de las adaptaciones teatrales, a muchos de los protagonistas del libro. Con todo, los dramaturgos están confrontados al problema que consiste en pasar del tiempo de la lectura -variable según los individuos y las circunstancias- al incompresible de la representación propiamente dicha. Las elipsis no bastan para subsanar esta necesidad. El análisis del tratamiento escénico aplicado a la pareja ducal permite poner de manifiesto dos nuevos conceptos operatorios complementarios: la condensación y la invención.

La condensación de los capítulos en torno a algunos personajes privilegiados resulta un procedimiento eficaz que consiste en juntar en un solo momento teatral varios momentos del tiempo de la novela.

Así, para Nele Paxinou, el bueno de Sancho es demasiado fiel como para atreverse a engañar a su señor inventando el encanto de la bella Dulcinea. La paternidad de la burla recae en el duque y la duquesa. A Josefa y Carmelo, dos personajes que cumplen la función de recitadores en esta versión, les toca avisar así al público:

\footnotetext{
2 El oasis de los clásicos.
} 
"La señorita Dulcinea del Toboso ha sufrido un hechizo (...) Es una broma que el duque y la duquesa quieren hacer creer al señor don Quijote."

La dramaturga se exime así de representar directamente la anécdota de las tres campesinas manipuladas por Sancho y preserva su visión ingenua y valorizante del escudero en detrimento de los duques que se presentan como grotescos y odiosos.

Por su parte, Georges Berdot aumenta todavía más la densidad informativa de la secuencia en la que vemos a una dueña relatar al pinche -en realidad al público- el encuentro de su ama y del caballero errante. Evoca a la vez el seudo hechizo, la flagelación expiatoria y el nombramiento de Sancho al gobierno de su ínsula. Estos tres acontecimentos relevantes, espaciados en varios capítulos, están así cunfundidos en un relato breve entre dos personajes.

El papel desempeñado por los duques en la economía dramática permite también referir hechos anteriores en la diégesis o evocar situaciones futuras. Cumplen así una función a la vez narrativa y explicativa.

El procedimiento de condensación puede también aplicarse a un personaje, pero entramos entonces en el campo de la invención.

La invención se refiere a un papel que junta varios actores de la novela. En la versión de Maryse Lefebvre, la Dama pertenece plenamente a esta categoría. En ella se concentran la duquesa, Altisidora y Dolorida. Al acoger a los dos protagonistas en su castillo en ruinas, interpreta alternativamente todos esos papeles.

Primero, en el interior de su casa solariega se convierte, para burlarse y divertirse, en el escenógrafo que representaban los duques en la novela. Después, se transforma en Altisidora que canta su pasión al caballero. Más adelante, aparece con los rasgos de Dolorida y organiza el famoso episodio de Clavileño.

Este personaje único con funciones múltiples, creado completamente por la dramaturga, contribuye de esta forma a disminuir las obligaciones temporales permitiendo no obstante la evocación de ciertos capítulos.

Pero el encuentro del caballero con la duquesa le otorga también a Cervantes la posibilidad de manifestar un juicio crítico sobre su época, práctica ya esbozada en la novela pero que alcanza entonces a su apogeo.

En estos episodios, la transformación del héroe en verdadero bufón o gracioso por sus huéspedes le confiere licencia absoluta. No obstante, la coherencia novelesca del hidalgo le prohibe adoptar esta imagen caricaturesca, si bien ocupa su función. Por contra, Sancho, su doble, se cuela en el papel con admirable holgura que favorecen su físico, su sólida sensatez de villano, su facundia 
inextinguible. En ese nuevo decorado de palacio, da rienda suelta a los talentos que se le suponía.

Amparado tras un estatuto eminentemente permisivo, el escudero se entrega entonces con júbilo a una crítica acerba del poder. Su insolencia (falsamente) ingenua ya no conoce límites. Pese que el duque le ha prometido el puesto tan ansiado de gobernador, el bueno de Sancho se resiste a separarse de su rucio favorito; irónicamente, la duquesa le aconseja que se lo lleve consigo. Con mucha seriedad, el nuevo magistrado replica ${ }^{3}$ :

«No piensa vuestra merced, señora duquesa que ha dicho mucho (...) ; que yo he visto ir más de dos asnos a los gobiernos, y que llevase yo el mío no sería cosa nueva.»

Esta impertinente verdad colma de júbilo a la interlocutora, así como su esposo se regocija por una desfachatez de semejante índole; durante una cacería, al explicar al escudero la importancia y las virtudes de tal actividad para los gobernadores, oye esta réplica ${ }^{4}$ :

"Mía fe, señor, la caza y los pasatiempos más han de ser para los holgazanes que para los gobernadores."

Sancho cumple con su papel de bufón cuerdo, el único que pueda guasearse del príncipe, decirle verdades que nadie más se atrevería a proferir.

Las transposiciones que ponen en escena a los personajes del duque y de la duquesa no dan muestra de la relativa indulgencia que Cervantes manifiesta respecto a la pareja ducal. En la novela, la gentileza y la generosidad que demostraban atenuaban un poco la inconstancia de su comportamiento, pero las versiones teatrales se muestran particularmente crueles con ellos, al llevar la crítica y la condena a su más alto grado.

En el momento en que los señores piensan divertirse - conforme a la novela - a costa de sus invitados que consideran "ridículos» y "grotescos» la escenografía de Nele Paxinou invierte de modo radical los puntos de vista. La dramaturga presenta al duque y a la duquesa como mamarrachos insustanciales, fachadas sociales coruscantes fabricadas en torno a un monstruoso egoísmo y una falta total de humanidad. Meras cáscaras vacías e irrisorias, pasan por los bufones de los que querian mofarse.

3 Don Quijote, II-33.

4 Don Quijote, II-34. 
Si, en la novela, Cid Hamed Ben Engeli los tenía por tan necios como sus huéspedes, la transposición de Nele Paxinou los cubre de un ridículo redhibitorio que recae sobre le potestad que representan y que resulta así descalificada para el espectador. Josefa y Carmelo, personajes ya citados, resumen en un breve diálogo el sentimiento general:

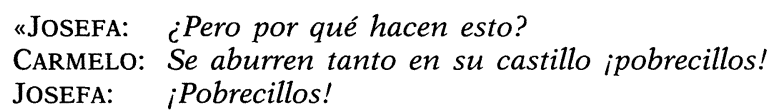

El tono de falsa conmiseración no deja equívoco en cuanto a la poca consideración que les tienen a los duques.

Georges Berdot se muestra todavía más determinado en su crítica. Toda la escenografía organiza el episodio como una confrontación entre la orgullosa aristocracia y el universo de los humildes, en una reactualización francamente política y polémica.

Rocinante inaugura el ciclo de la revancha al "aliviarse» sin vergüenza sobre las botinas del duque, pero antes ya los criados apreciaban muy poco los manejos de sus amos, como el cocinero que refunfuña:

"¡Burlarse así de los pobres y de los locos ... prefiero mis hornos!»

Georges Berdot es también el único que trata de las hazañas de Sancho en su puesto de gobernador, y lo hace según las mismas opciones. La transposición teatral del episodio precisa muy bien la realidad y la extensión de los poderes del escudero, más allá de la broma inicial:

"Su librea de gobernador es una pero se ha recomendado al burgomaestro que lo deje gobernar. Y entonces será dueño de hacer como le plazca.»

El patán convertido en señor admira a su entorno por la sagacidad de sus juicios. Confunde con brío a la prostituta que acusa a un ganadero demasiado ingenuo de haberla forzado y, para el asombro de todos dilucida el misterio del dinero ocultado en una cañaheja.

Con motivo de este lance, el dramaturgo introduce una acometida más contra la aristocracia que no le debe nada a Cervantes. En la novela, el querellante y su adversario son de condición semejante, dos ancianos anónimos, mientras que en la pieza una didascalia convierte los pleitantes en: "un anciano y un aristócrata joven». Así, la escena ya no ilustra sólo la codicia y la astucia de un individuo frente a una figura semejante sino que se convierte 
en un enfrentamiento de edades y de estamentos en el que la nobleza se asemeja a una forma de explotación y de enriquecimiento ilícito metaforizado por el episodio de la cañaheja.

La perspicacia sublime del patán-magistrado se vuelve en contra de la burla imaginada por los duques. En lugar de los juicios de un bufón, se suceden los indicios de una deslumbrante clarividencia y el mayordomo, al principio cómplice de los duques pero seducido por la inteligencia de Sancho, confiesa su admiración sincera: « $\mathrm{Me}$ admira usted!» declara al escudero inquieto por su primera actuación.

Además de la libertad de la palabra, el gobernador provisorio alcanza la libertad de acción; su manera de usarla asusta a los instigadores de la burla que ven cómo su supremacía hereditaria está contestada por las decisiones atinadas de un paleto analfabeto. De hecho, todo el pueblo empieza ya a creer que Sancho es un verdadero gobernador y a alegrarse del nombramiento de un edil tan honrado y cuerdo como virtuoso y competente. Esta situación imprevista inquieta al duque:

"iSi que es increible! Este Sancho es extraño. Lleva siete días gobernando y sigue sin cometer un disparate siquiera. No me gusta eso. $Y$ que un paleto que no sabe leer ni escribir gobierne tan bien como un hombre de calidad... no me satisface nada.»

Más aún, sus propios lacayos manifiestan una especie de solidaridad de clase con su hermano de condición, se alegran de sus éxitos y hacen votos por su triunfo total. Se vuelve muy peligroso dejar a Sancho en su puesto y se prepara una estratagema para obtener su partida. El ataque de Barataria se convierte en la transposición un recurso indispensable e improvisado para cerrar la experiencia, demasiado peligrosa en su evolución para los instigadores. Georges Berdot afirma con claridad a su espectador lo que Cervantes dejaba solamente suponer a su lector.

Cada versión teatral pone así de relieve unos ejes preferentes, unas visiones peculiares pero no obstante convergentes en un plano: la duquesa encarna la arrogancia de una clase privilegiada, celosa de su poder y potestad, que testimonia de un desprecio sin límites por unas clases consideradas inferiores.

En este final del siglo $\mathrm{xx}$, los dramaturgos identifican a don Quijote con un defensor de los valores morales y políticos que, a través de su compromiso personal, podrían permitir el nacimiento de un mundo mejor. Bajo formas renovadas, la Edad de Oro sigue siendo una aspiración, una utopía profundamente anclada en el inconsciente colectivo contemporáneo.

Claude Labère 